\title{
SCIENTIFIC REPORTS

\section{Effective Removal of Levofloxacin from Pharmaceutical Wastewater Using Synthesized Zinc Oxid, Graphen Oxid Nanoparticles Compared with their Combination}

\author{
Christine M. El-Maraghy ${ }^{1}$, Ola M. El-Borady ${ }^{2} \&$ Omnia A. El-Naem ${ }^{1 *}$
}

The presence of antibiotic traces in the aquatic system due to the inefficient treatment of the pharmaceutical wastewater represented threats, such as bioaccumulation and antibiotic-resistance, to the environment and human health. Accordingly, for the first time, the current work utilized the photocatalytic degradation and the adsorption approach for Levofloxacin (LEVO) in pharmaceutical wastewater using new designed nano aspects. Therefore, spherical Zinc oxide nanoparticles (ZnONP) sized $17 \mathrm{~nm}$ and ultrathin sheet-like structure graphene oxide nanosheets (GONS) with layer thickness $\sim 5 \mathrm{~nm}$ were fabricated separately or in a combination between them then characterized via Transmission Electron Microscope (TEM), Scanning Electron Microscope (SEM), X-Ray Diffraction (XRD), Fourier Transforms Infrared Spectroscopy (FTIR), absorption spectra (UV-Vis) and BrunauerEmmett-Teller (BET). Additionally, several parameters were investigated to evaluate the potential of the removal process, such as $\mathrm{pH}$, the exposure time to $\mathrm{UV}$ radiation, the type and concentration of the nanoparticles (NPs) and the initial concentration of the drug using a mixed fractional factorial design. The most effective parameter for LEVO removal was the NPs type followed by the initial drug concentration. Furthermore, an RP-HPLC/UV method was developed and validated for measuring the percentage of removal for LEVO drug. The highest percentage removal for both 50 and $400 \mu \mathrm{g} \mathrm{mL}^{-1}$ LEVO was $99.2 \%$ and $99.6 \%$, respectively, which was achieved using ZnONP/GONS combination at $\mathrm{pH} 9 \pm 0.05$ and UV light exposure time $120 \mathrm{~min}$. In addition, the negative antibacterial activity of the treated wastewater sample confirmed the drug removal. The established protocol was successfully applied on wastewater samples collected from a pharmaceutical company that encouraged researchers to mainstream this design to be applied on other pharmaceutical wastewater drugs.

The environmental and human risks due to the occurrence of antibiotics in the aquatic environment, even in low concentration, have attracted considerable concern. Antibiotics have been detected worldwide in the aquatic environment, indicating their inefficient removal from wastewater utilizing the conventional methods of water treatment ${ }^{1}$. The presence of antibiotics in the ordinary water comes mainly from the discharges of sewage treatment plants (STPs) and pharmaceutical manufacturing plants ${ }^{2-5}$. The presence of antibiotic traces in the aquatic system can cause bio-accumulation and resistance in bacterial populations, making them ineffective for treatment in the near future ${ }^{6}$. Therefore, there is a serious need to merely develop a simple, effective and low-cost method for removing of such contaminants. In this current study, the LEVO (Fig. 1, supplemental materials) was chosen as an example of antibacterial fluoroquinolones (FQs) and one of the essential medicines listed by the World Health Organization's (WHO) ${ }^{7}$. Their presence in the aquatic environment can cause development of antibiotic-resistant bacteria $^{6}$ and genotoxicity ${ }^{8}$. In addition, FQs are prescribed largely in human and veterinary uses and are partially metabolized in the body, so a significant amount of the drug is excreted in the same form which definitely

${ }^{1}$ Analytical Chemistry Department, Faculty of Pharmacy, October University for Modern Sciences and Arts (MSA), 11787 6th October City, Cairo, Egypt. 'Institute of Nanoscience and Nanotechnology, Kafrelsheikh University, Kafrelsheikh, 33516, Egypt. *email: dr.omniali@gmail.com 

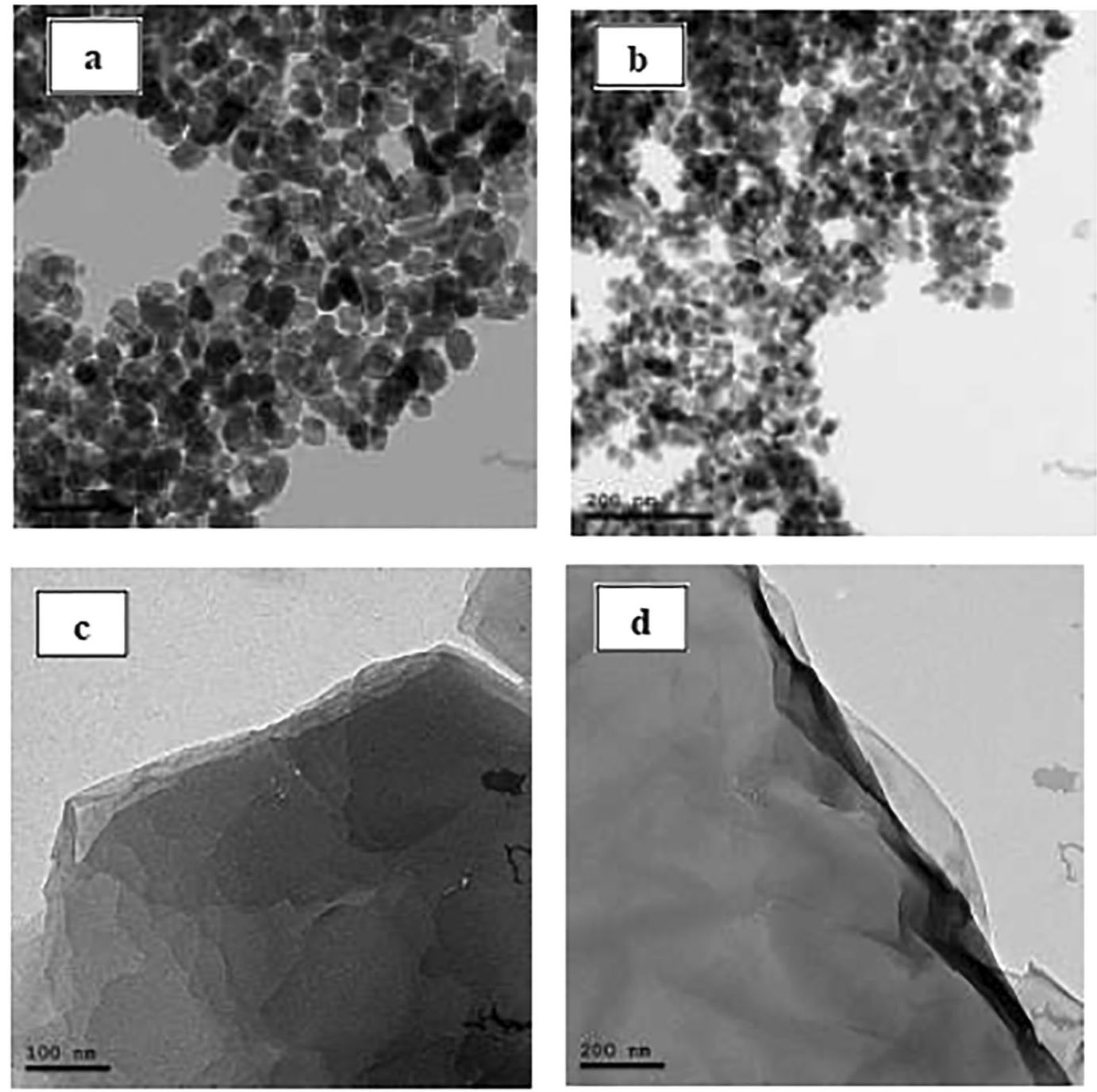

Figure 1. TEM image of ZnONP taken at different scale (a) $100 \mathrm{~nm}$ and (b) $200 \mathrm{~nm}$ and GONS at (c) $100 \mathrm{~nm}$ and (d) $200 \mathrm{~nm}$.

affects the aquatic ecosystem ${ }^{9}$. There are many techniques used for wastewater treatment and remediation like conventional methods such as biological processes, coagulation/flocculation/sedimentation ${ }^{10-12}$ and by sand filtration or ozonation ${ }^{13,14}$ which are not designed to remove highly polar contaminants as the antibiotics. There are non-conventional methods such as oxidation, adsorption, reverse osmosis, ion exchange and combined meth$\mathrm{ods}^{15}$. Two techniques were demonstrated for an efficient removal of the antibiotic from wastewater: the advanced oxidation process (AOPs) and the adsorption technique. The AOPs depends on the photocatalytic degradation of organic compounds and has the advantage of being environment friendly as it converts the organic pollutants into $\mathrm{CO}_{2}$ and $\mathrm{H}_{2} \mathrm{O}^{16}$. The adsorption technique is commonly used to describe the tendency of the molecules in fluid phase to adhere to a solid surface ${ }^{15}$ and has the advantage of simplicity of design and operation and is relatively inexpensive $e^{2}$. The literature survey revealed several photocatalytic degradations of LEVO using different photocatalysts such as the $\mathrm{TiO}_{2}$ with drug degradation not more than $90 \%{ }^{17-19}, \mathrm{Bi}_{2} \mathrm{WO}_{6}$ nanocuboids with approximately $80 \%$ degradation in $150 \mathrm{~min}^{20}, \mathrm{Ag} / \mathrm{AgBr} / \mathrm{BiOBr}$ microplates under visible light with degradation about $74 \%$ under 90 min of irradiation ${ }^{21}$ and a combination of $\mathrm{Ag}_{2} \mathrm{O} / \mathrm{TiO}_{2}$ quantum dots under visible light with $81 \%$ of LEVO degradation in $90 \mathrm{~min}^{22}$. There was a reported method for the removal of FQs using the magnetite pectin as adsorbent ${ }^{23}$. The need for a simple, effective and low-cost method entered the line with the emergence of a new science: the nanotechnology which has entered its applications in many fields. The NPs are considered potent adsorbents, disinfectants and catalysts and they are also used as sensors due to their high specific surface area expressed to large reactivity ${ }^{24}$. In this work, two types of metal oxide nanoparticles were employed: $\mathrm{ZnONP}$ and GONS. ZnONP was used as an efficient alternative disinfectant for wastewater system because of its catalytic activity ${ }^{25}$ and it has a small particle size (hence high surface area) which aids in its efficiency ${ }^{26}$. ZnONP of concentration $0.34-1.42 \mu \mathrm{g} \mathrm{L}^{-1}$ was used in treated wastewater in Europe in $2008^{27}$ and it was increased to $1.7-21 \mu \mathrm{g} \mathrm{L}^{-1}$ in $2014^{28}$. In recent years, GONS, a heavily oxygenated graphene derivative, has been extremely explored for biomedical applications as well as in membranes for water treatment ${ }^{29,30}$. GO has a high surface area 
with a large number of polar oxygen-containing functional groups ${ }^{31}$, which makes it a valuable adsorbent to be used in removal of organic compounds. The aim of the present work was to develop an efficient simple method for pharmaceutical wastewater treatment containing LEVO, as a model of antibacterial FQS in wastewater, and to achieve higher removal for the LEVO than the other published works. A mixed fractional factorial design was carried out to optimize the removal process and to study the effect of various factors affecting the LEVO removal. A protocol using RP-HPLC/UV has been developed and validated for monitoring of LEVO throughout the work of treatment. The optimum set of conditions for the highest removal percentage was applied on pharmaceutical wastewater samples. The introduction of such a protocol for the treatment of pharmaceutical wastewater will help to improve human and ecological health.

\section{Experimental}

Chemicals and samples. Standard LEVO was obtained from Sanofi pharmaceutical company (Egypt). For the preparation of NPs: zinc acetate dihydrate, sodium hydroxide, sulfuric acid (95\%), sodium nitrate (99.9\%), and potassium permanganate $\left(99.9 \%, \mathrm{KMnO}_{4}\right)$ were purchased from sigma Aldrich; Graphite (99.99\%) and hydrogen peroxide $\left(\mathrm{H}_{2} \mathrm{O}_{2} 36 \%\right)$ from Alfa Aesar; Methanol HPLC grade (99.8\%) from LobaChemie PVT.LTD, India; and Potassium dihydrogen phosphate and ortho-phosphoric acid from Sharlau, Spain. For the antibacterial activity test: saline solution, barium chloride, sulphuric acid (ADWIC company, Egypt) and Mueller-Hinton agar were used.

Instruments. Morphology information including the particle size and shape of fabricated NPs were measured using the Transmission Electron Microscopy (HR-TEM), JOEL JEM-2010 operating at an accelerating voltage of $200 \mathrm{kV}$ attached with Gatan digital camera Erlangshen ES500. Structural composition was achieved by FT-IR measurements via JASCO spectrometer; samples were scanned from $4000-400 \mathrm{~cm}^{-1}$. The crystallography of the synthesized NPs powder and patterns of X-Ray Diffraction were analyzed using SHIMADZU XRD 6000 diffractometer with CuKal radiation $\left(\mathrm{k}=1.54056 \mathrm{~A}^{\circ}\right)$ operating at voltage and current of $40.0(\mathrm{kV})$ and 30.0 $(\mathrm{mA})$, respectively. The pore characteristics such as average pore diameter and specific surface area of the NPs were determined according to the Brunauer-Emmett-Teller (BET) and Barrett-Joyner-Halenda (BJH) methods. HPLC Agilent 1200 series, with a multiple wavelength detector, microvacuum degasser and thermostatic column compartment, was used for measuring the LEVO concentration throughout the work of treatment. ChemStation software (Agilent Technologies, Germany) was used for displaying the results. Phenomenex $\mathrm{C}_{18}$ column $(150 \mathrm{~mm}$ $\times 4.6 \mathrm{~mm}, 5 \mu \mathrm{m}$ particle size) was obtained from Agilent Technologies, Polo Alto, CA, USA, and the $\mathrm{pH}$-meter was Jenway3505, UK. The experimental design was performed using design Expert Software version 7.0 (Stat-Ease Inc., Statistics made easy, Minneapolis, USA). Shimadzu UV-visible 1800 spectrophotometer, Japan, was connected to UV-Probe 2.32 software. The incubator was used for the antibacterial activity test (Jouan, USA).

Synthesis of Zinc oxide nanoparticles (ZnONP). ZnONP has been synthesized according to Beek et al. method $^{32}$ and Weller et al. ${ }^{33}$ through the hydrolysis method of zinc acetate dihydrate by $\mathrm{KOH}$ at low temperature not more than $70^{\circ} \mathrm{C}$ in alcoholic medium (solvothermal method), but with some slight modification. Firstly, 3.35 mmoL of Zinc acetate dihydrate was dissolved in $32 \mathrm{~mL}$ methanol and mixed very well to obtain a homogenous solution using magnetic stir; another solution of $6.60 \mathrm{mmoL} \mathrm{NaOH}$ was prepared in methanol. Then, $\mathrm{NaOH}$ solution was added dropwise to the zinc acetate solution while carefully adjusting the temperature solution at $60^{\circ} \mathrm{C}$ with vigorous stirring. The solution became turbid with a white precipitate upon addition of the hydroxide indicating the formation of $\mathrm{ZnONP}$. After the addition of $\mathrm{NaOH}$ was completed, the solution mixture was left to be stirred for $120 \mathrm{~min}$ while the heater is off. Finally, the precipitate formed was left to settle down and was washed four times with methanol then dried in the oven at $100^{\circ} \mathrm{C}$.

Synthesis of graphene oxide nanosheets (GONS). GONS was synthesized via Improved Hummer's $\operatorname{method}^{34}$. In this method, the graphite was used as the precursor for the production of graphene while a strong oxidation of the graphite was done leading to a weak $\pi-\pi$ stacking between the graphite layers; herein, several oxygenated functional groups are inserted onto the surface of GO. This is followed by a disruption for the $\mathrm{sp}^{2}$ graphite structure which makes it possess many intrinsic characteristics such as electrical and mechanical properties $^{35,36}$. Briefly, a solution of sulfuric acid $(25 \mathrm{~mL})$ containing $0.5 \mathrm{~g}$ of graphite was prepared, followed by adding $0.5 \mathrm{~g}$ of $\mathrm{NaNO}_{3}$ with moderate stirring $(20 \mathrm{~min})$. After that, the mixture solution was kept at $10^{\circ} \mathrm{C}$ in an ice bath. When reaching the desired temperature, $3 \mathrm{~g}$ of $\mathrm{KMnO}_{4}$ was gradually added over $15 \mathrm{~min}$ and the solution was kept in a temperature of not more than $10^{\circ} \mathrm{C}$; this will enhance the homogeneity of the formed GO nanosheets. The reaction solution was left to be stirred at $35^{\circ} \mathrm{C}$ overnight. At that time, $50 \mathrm{~mL}$ of deionized water was added dropwise. While addition, a remarkable increase in the temperature was observed; therefore, we adjusted it so as not to exceed $90^{\circ} \mathrm{C}$. After that, the solution was left to be stirred at the same temperature for $60 \mathrm{~min}$. Finally, $140 \mathrm{~mL}$ of warmed deionized water was slowly added to the solution followed by addition of $5 \mathrm{~mL}^{\circ} \mathrm{H}_{2} \mathrm{O}_{2}$; the solution color turned into brownish yellow indicting the formation of GO. The decantation was done for the mother liquor, then the brown precipitate was washed several times by distilled water to remove any unreacted substances, and then it was filtered and dried in the oven at $60^{\circ} \mathrm{C}$.

Preliminary studies. In the present investigation, standards of LEVO $\left(100 \mu \mathrm{g} \mathrm{mL}^{-1}\right)$ were prepared in distilled water. Studies were performed to assess the effect of presence and absence of photocatalyst with UV exposure. The LEVO standard solution was carried in a UV chamber and exposed to a UV lamp $(254 \mathrm{~nm}, 1012 \mu \mathrm{W}$ $\mathrm{cm}^{-2}$ ) at variable durations ( $60 \mathrm{~min}$ or $120 \mathrm{~min}$ ) in the presence or absence of the photocatalytic NPs (ZnONP or GONS or combination of both) and at $2 \mathrm{pH}$ units (7 and 9). After the incubation time, the samples were analyzed using UV-Vis spectrophotometer. 


\begin{tabular}{|l|l|l|}
\hline Factor name & Low level (-1) & High level (1) \\
\hline $\mathrm{pH}$ & 7 & 9 \\
\hline Time of UV exposure & $60 \mathrm{~min}$ & $120 \mathrm{~min}$ \\
\hline Drug Conc. & $50 \mathrm{ug} \mathrm{mL}-1$ & $400 \mathrm{ug} \mathrm{mL}$ \\
\hline $\mathrm{ZnO}$ & $0.4 \mathrm{gL}^{-1}$ & $1 \mathrm{gL}^{-1}$ \\
\hline $\mathrm{GO}$ & $0.4 \mathrm{gL}^{-1}$ & $1 \mathrm{gL}^{-1}$ \\
\hline $\mathrm{ZnO}: \mathrm{GO}$ & $0.4: 1 \mathrm{gL}^{-1}$ & $1: 0.4 \mathrm{gL}^{-1}$ \\
\hline
\end{tabular}

Table 1. The factors and their levels used for the mixed fractional factorial design experiment.

Experimental design. The mixed fractional factorial design $\left(2^{4} \times 3^{1}\right)$ was used to evaluate the effect of four factors; the $\mathrm{pH}$, the exposure time to UV radiation, the type and concentration of the NPs and the initial concentration of LEVO drug. Two levels for each factor were chosen: low level $(-1)$ and high level $(+)$. Moreover, for the type of the NPs, three levels were assessed (ZnONP, GONS and a combination of both) as shown in Table 1. Forty-eight samples were prepared with various levels of the factors to choose the optimum conditions for the highest removal of LEVO drug, as shown in Table 2. The samples were analysed after filtration using RP-HPLC/ UV. The removal percentage was calculated as follows:

$$
\text { \%removal }=\left(C^{\prime}-C\right) / C^{\prime} \times 100,
$$

where $\mathrm{C}^{\prime}$ is the concentration of intact drug solution and $\mathrm{C}$ is the concentration of the treated drug solution.

Chromatographic conditions. The optimum result was obtained using Phenomenex $\mathrm{C}_{18}(150 \mathrm{~mm} \times$ $4.6 \mathrm{~mm}, 5 \mu \mathrm{m}$ particle size i.d.) and mobile phase consisting of methanol: phosphate buffer ( $\mathrm{pH} 6)$ in a ratio $50: 50 \mathrm{v} / \mathrm{v}$. The $\mathrm{pH}$ of the buffer was adjusted using orthophosphoric acid. Isocratic elution was employed at flow rate $1 \mathrm{~mL} \mathrm{~min}{ }^{-1}$ and the UV detection at $294 \mathrm{~nm}$. The samples were filtered before injection using syringe filter paper $(0.45 \mu \mathrm{m}, \mathrm{PTFE})$.

Construction of calibration curve and validation. The calibration curve was linear in the concentration range $\left(10-500 \mu \mathrm{g} \mathrm{mL}^{-1}\right)$. The obtained regression equation $(y=25.023 \mathrm{x}-22.852)$ was used to calculate the concentration of LEVO residual after each degradation trial. The validation procedure was done according to the ICH guidelines ${ }^{37}$ for determination of linearity, accuracy, precision, specificity, limit of detection (LOD) and limit of quantification (LOQ).

Application to pharmaceutical wastewater. The optimum conditions for degradation of LEVO were applied on incurrent samples of pharmaceutical wastewater. The wastewater was obtained after three cycles from the cleaning production lines of one batch of LEVO. According to the manufacturer's protocol, the cleaning procedure was performed using boiling distilled water for three successive cycles. Samples were collected after each washing cycle and pooled together; their $\mathrm{pH}$ was measured and then they were stored at $-20^{\circ} \mathrm{C}$. The concentration of LEVO in the three collected samples was measured three times each using RP-HPLC/UV and the $\mathrm{pH}$ was adjusted to nine, then the samples were exposed to UV radiation $\left(254 \mathrm{~nm}, 1012 \mu \mathrm{W} \mathrm{cm}{ }^{-2}\right)$ for $120 \mathrm{~min}$ in the presence of a combination of ZnONP:GONS $\left(0.4: 1 \mathrm{~g} \mathrm{~L}^{-1}\right)$. At the end of the exposure time, the samples were filtered and injected into the HPLC system as mentioned previously.

Antibacterial activity test using agar diffusion method. To confirm the effective removal of LEVO and the lack of its antimicrobial activity, the agar diffusion method was done on the treated water sample achieving the optimized conditions compared with the untreated one ${ }^{38}$. In a typical experiment, a $100 \mu \mathrm{L}$ of fresh culture of Escherichia coli ATCC 29522 (approximately $10^{8} \mathrm{CFU} \mathrm{mL}^{-1}$ ) was uniformly spread onto Mueller-Hinton agar plates using a sterile swab. The inoculated plates were allowed to dry at room temperature for 20 min using a sterilized cup-borer, and two wells were made in the agar. The treated and untreated water samples $(100 \mu \mathrm{L})$ were dispensed into the wells. The Plates were incubated at $37^{\circ} \mathrm{C}$ for 18 hours. After the incubation period, the diameter of the zone of inhibition for each sample was measured.

\section{Results and discussion}

Synthesis and characterization of ZnONP and GONS. The transmission electron microscope (TEM). The morphological essential information for the prepared NPs was examined via the TEM imaging. The TEM images obtained for a suspended solution of ZnONP represented in Fig. 1a,b showed a high uniform size of elongated spherical-shaped NPs that possessed an average size of $17 \mathrm{~nm}$. On the other hand, in the present context, the GONS was produced by oxidation of graphite using modified Hummers method, leading to a combination between $\mathrm{KMnO}_{4}$ and $\mathrm{H}_{2} \mathrm{SO}_{4}$ producing diamanganese heptoxide $\left(\mathrm{Mn}_{2} \mathrm{O}_{7}\right)$, an active oxidant that oxidizes the graphite-unsaturated double bonds of the formed graphene oxide ${ }^{39}$. The TEM image for GONS shown in Fig. 1c,d exhibited an ultrathin sheet-like structure, with a smooth surface, while several folds and wrinkles were observed especially at the edges. In addition, the TEM result sufficiently indicates two-dimensional nanosheets produced for GO with approximately $6 \mu \mathrm{m}$ in size and with layer thickness of about $5 \mathrm{~nm}$.

The scanning electron microscope (SEM). The morphology examination and the surface characterization of the synthesized NPs were also observed via SEM. A micrograph in Fig. 2a presented the SEM image of $\mathrm{ZnONP}$, while its size was predicted to be around $17 \mathrm{~nm}$, having a spherical shape with high order and 


\begin{tabular}{|c|c|c|c|c|c|c|c|}
\hline Run no & pH & time & $\begin{array}{l}\text { Levo } \\
\text { comc. }\end{array}$ & $\begin{array}{l}\text { NP } \\
\text { conc }\end{array}$ & NP type & $\begin{array}{l}\text { Average peak } \\
\text { area }\end{array}$ & Degradation \% \\
\hline 1 & -1 & 1 & -1 & -1 & ZnO:GO & 7 & $99.34 \%$ \\
\hline 2 & 1 & 1 & 1 & -1 & $\mathrm{ZnO}$ & 1423 & $29.87 \%$ \\
\hline 3 & -1 & -1 & 1 & 1 & ZnO:GO & 50 & $97.54 \%$ \\
\hline 4 & 1 & -1 & 1 & -1 & GO & 225.9 & $88.87 \%$ \\
\hline 5 & 1 & 1 & 1 & 1 & $\mathrm{ZnO}$ & 1348.8042 & $33.52 \%$ \\
\hline 6 & 1 & 1 & 1 & 1 & GO & 217 & $89.31 \%$ \\
\hline 7 & 1 & 1 & -1 & 1 & ZnO:GO & 22 & $97.92 \%$ \\
\hline 8 & 1 & -1 & -1 & -1 & $\mathrm{ZnO}$ & 743 & $29.77 \%$ \\
\hline 9 & 1 & -1 & -1 & -1 & ZnO:GO & 28 & $97.35 \%$ \\
\hline 10 & -1 & -1 & 1 & -1 & ZnO:GO & 70 & $96.55 \%$ \\
\hline 11 & -1 & -1 & -1 & 1 & GO & 86 & $91.87 \%$ \\
\hline 12 & -1 & 1 & 1 & -1 & GO & 222 & $89.06 \%$ \\
\hline 13 & -1 & -1 & -1 & -1 & ZnO:GO & 25 & $97.64 \%$ \\
\hline 14 & -1 & 1 & -1 & -1 & GO & 112.03658 & $89.41 \%$ \\
\hline 15 & -1 & -1 & 1 & -1 & GO & 255 & $87.43 \%$ \\
\hline 16 & -1 & -1 & -1 & 1 & ZnO:GO & 30 & $97.16 \%$ \\
\hline 17 & -1 & -1 & 1 & 1 & $\mathrm{ZnO}$ & 1411.43237 & $30.44 \%$ \\
\hline 18 & -1 & -1 & -1 & -1 & GO & 112.95795 & $89.32 \%$ \\
\hline 19 & 1 & 1 & -1 & -1 & GO & 109.23647 & $89.68 \%$ \\
\hline 20 & -1 & -1 & 1 & -1 & $\mathrm{ZnO}$ & 1440.86401 & $28.99 \%$ \\
\hline 21 & 1 & -1 & 1 & 1 & GO & 188 & $90.73 \%$ \\
\hline 22 & 1 & -1 & 1 & 1 & $\mathrm{ZnO}$ & 1431.43237 & $29.45 \%$ \\
\hline 23 & -1 & -1 & -1 & -1 & $\mathrm{ZnO}$ & 752 & $28.92 \%$ \\
\hline 24 & -1 & 1 & 1 & 1 & ZnO:GO & 44.5 & 97.81\% \\
\hline 25 & -1 & -1 & -1 & 1 & $\mathrm{ZnO}$ & 732 & $30.81 \%$ \\
\hline 26 & -1 & 1 & 1 & -1 & $\mathrm{ZnO}$ & 1400 & $31.00 \%$ \\
\hline 27 & 1 & -1 & -1 & -1 & GO & 133.50594 & $87.38 \%$ \\
\hline 28 & -1 & 1 & -1 & 1 & $\mathrm{ZnO}$ & 711 & $32.80 \%$ \\
\hline 29 & 1 & 1 & 1 & -1 & ZnO:GO & 16.01124 & $99.21 \%$ \\
\hline 30 & 1 & -1 & -1 & 1 & ZnO:GO & 40 & $96.22 \%$ \\
\hline 31 & -1 & 1 & 1 & -1 & ZnO:GO & 20 & $99.01 \%$ \\
\hline 32 & 1 & -1 & 1 & 1 & ZnO:GO & 66 & $96.75 \%$ \\
\hline 33 & 1 & 1 & 1 & 1 & ZnO:GO & 50 & $97.54 \%$ \\
\hline 34 & -1 & 1 & 1 & 1 & GO & 165 & $91.87 \%$ \\
\hline 35 & 1 & 1 & -1 & -1 & ZnO:GO & 3.93124 & $99.63 \%$ \\
\hline 36 & -1 & 1 & -1 & 1 & GO & 126 & $88.09 \%$ \\
\hline 37 & 1 & -1 & -1 & 1 & $\mathrm{ZnO}$ & 747 & $29.40 \%$ \\
\hline 38 & -1 & 1 & 1 & 1 & $\mathrm{ZnO}$ & 1348.6 & $33.53 \%$ \\
\hline 39 & 1 & -1 & 1 & -1 & ZnO:GO & 77 & $96.21 \%$ \\
\hline 40 & 1 & 1 & -1 & 1 & GO & 128 & $87.90 \%$ \\
\hline 41 & -1 & 1 & -1 & 1 & ZnO:GO & 28 & $97.35 \%$ \\
\hline 42 & 1 & -1 & 1 & -1 & $\mathrm{ZnO}$ & 1354 & $33.27 \%$ \\
\hline 43 & -1 & 1 & -1 & -1 & $\mathrm{ZnO}$ & 712 & $32.70 \%$ \\
\hline 44 & 1 & 1 & 1 & -1 & GO & 210 & $89.65 \%$ \\
\hline 45 & 1 & 1 & -1 & 1 & $\mathrm{ZnO}$ & 697 & $34.12 \%$ \\
\hline 46 & 1 & -1 & -1 & 1 & GO & 94.3 & $91.09 \%$ \\
\hline 47 & 1 & 1 & -1 & -1 & $\mathrm{ZnO}$ & 700.3 & $33.81 \%$ \\
\hline 48 & -1 & -1 & 1 & 1 & GO & 191 & $90.59 \%$ \\
\hline
\end{tabular}

Table 2. Design matrix for the mixed fractional factorial $\left(2^{4} \times 3^{1}\right)$ employed for LEVO photocatalytic degradation and results of the RP-HPLC.

arrangement. Furthermore, the SEM obtained for GONS depicted in Fig. 2b showed that GONS consists of crumpled thin sheets with some random aggregation. Moreover, clear folds on the surface of GONS were observed. The two-dimensional structure of GONS was a characteristic feature in the SEM image too.

The BET. The BET analysis was performed for the nano samples as an important tool of analysis to prove that the high catalyst active surface was ready for adsorption. The obtained isotherm (Figs. 2 and 3 supplemental 

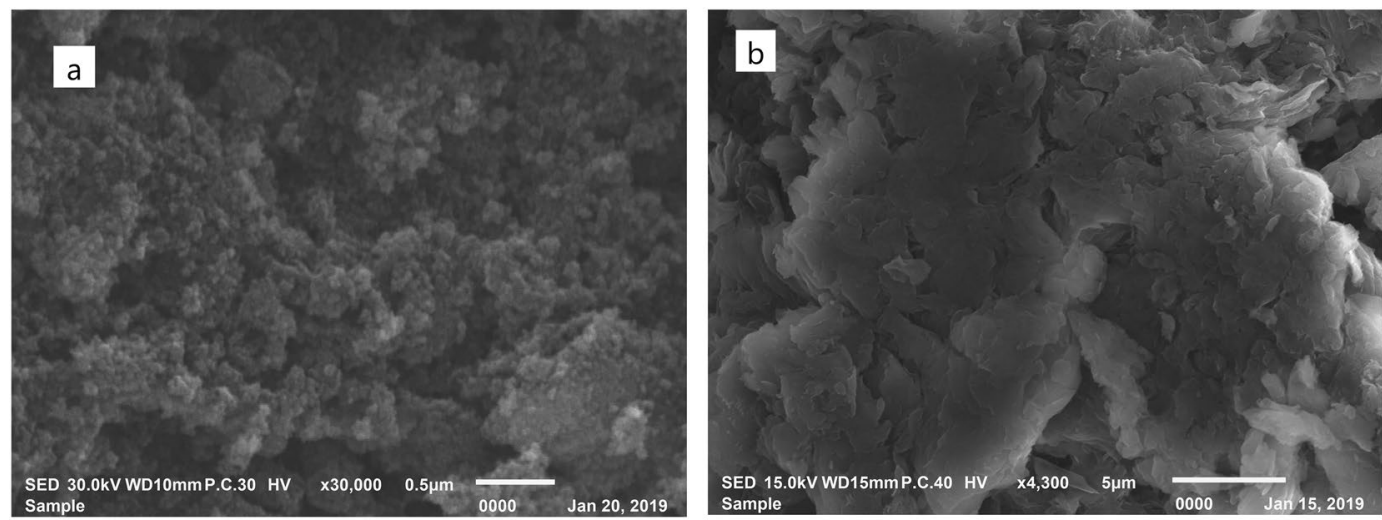

Figure 2. The SEM micrograph image of the synthesized (a) ZnONP and (b) GONS.
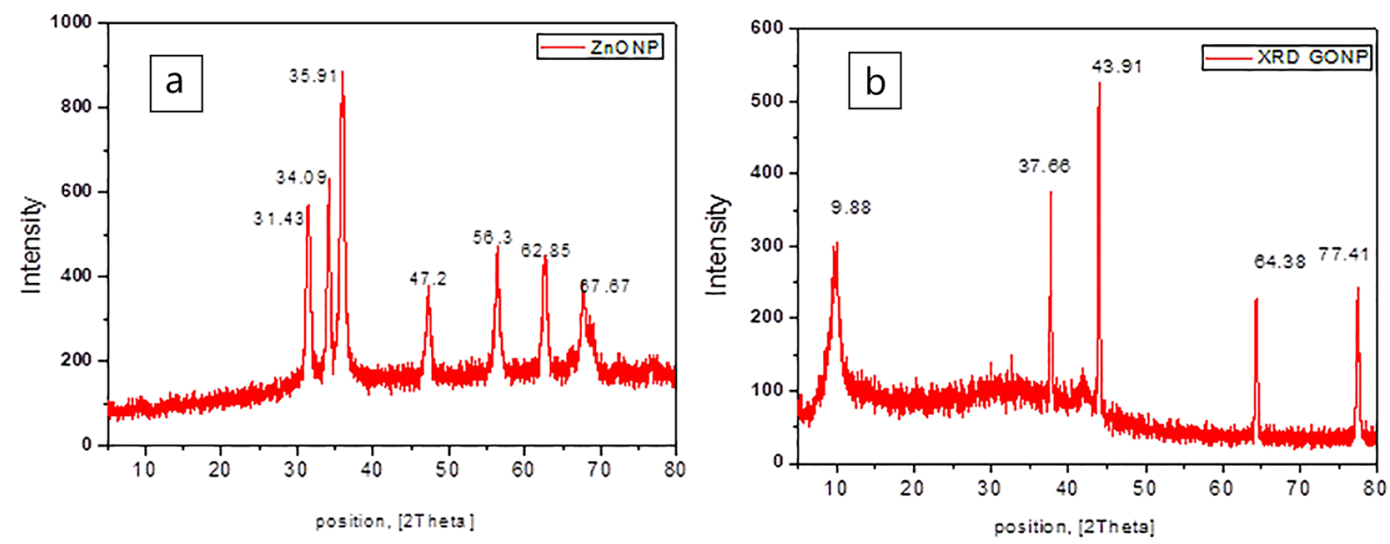

Figure 3. XRD pattern of (a) ZnONP and (b) GONS.

materials) indicated that the specific surface area of synthesized ZnONP and GONS were $27 \mathrm{~m}^{2} \mathrm{~g}^{-1}$ and $53 \mathrm{~m}^{2}$ $\mathrm{g}^{-1}$, respectively. The results revealed that the adsorption capacity of GONS will be superior to ZnONP due to its higher surface area. In addition, the presence of a hysteresis loop in isotherm of GONS confirms the formation of porosity over its surface that may lead it to be a highly effective material towards adsorption of the drug.

The X-ray diffraction (XRD). The crystallinity and the structure of the produced NPs were confirmed by subjecting the samples to the XRD analysis, while the magnitude and location of peaks will provide those relevant information. The XRD pattern of ZnONP (Fig. 3a) showed three peaks with $2 \theta$ at 31.43, 34.09 and 35.91 that may be corresponding to (100), (002) and (101), respectively. The position of those peaks revealed the presence of $\mathrm{ZnONP}$ in a hexagonal wurtzite structure. As reported in earlier studies, the minor boarding for XRD peaks at (100), (002) and (101) may be ascribed to the formation of spherical rather than rod nanoparticles ${ }^{40}$. The other three peaks at scattering angles $2 \theta$ of 47.2, 56.3 and 62.85 may be corresponding to (102), (110) and (200) crystal plane, respectively.

The XRD pattern for GONS (Fig. 3b) showed weak and sharp reflection peak at $2 \theta$ of $9.88^{\circ}$ attributed to the (001) reflection plan for GONS with layer-to-layer distance (d-spacing) within $8.8 \mathrm{~A}^{\circ}$ compared with that appearing for graphite only at $3.4 \mathrm{~A}^{\circ}$ and this increasing in $\mathrm{d}$-spacing was illustrated by Yan et al. ${ }^{41}$, and they attributed it to the introduction of hydroxyls and carboxyls functional groups during the oxidation onto the surface of used graphite confirming formation of GONS.

Fourier transforms infrared spectroscopy (FT-IR). FT-IR measurements were done to verify the bond structure of nanoparticles. Figure $4 \mathrm{a}$ shows the infrared absorption spectrum of $\mathrm{ZnONP}$ scanned in the range from $4000-400 \mathrm{~cm}^{-1}$. The spectrum exhibited the appearance of a band centered at $3430 \mathrm{~cm}^{-1}$ due to the O-H vibration mode that may present from the alcohol adsorbed on the ZnONP surface. Moreover, two weak and broad bands due to the symmetric stretching of C-O. C-O-C groups were located at 1473 and $1384 \mathrm{~cm}^{-1}$, respectively. Also, the peaks at 1631 and $889 \mathrm{~cm}^{-1}$ can be assigned to $\mathrm{Zn}-\mathrm{O}$ stretching and deformation vibration mode, respectively, whereas the peaks that appear below $1000 \mathrm{~cm}^{-1}$ in the metal oxides IR chart are considered as fingerprints for existence of metal oxide. All the above frequencies observed in the IR chart of ZnONP were in accordance with the results obtained previously by $\mathrm{H}$. Kumar and R. Rani ${ }^{42}$. Moreover, the GONS FT-IR spectrum in Fig. $4 \mathrm{~b}$ exhibited a peak around $3425 \mathrm{~cm}^{-1}$ due to the stretching vibrations of the $\mathrm{O}-\mathrm{H}$ group and another two attached sharp peaks were observed at $1735 \mathrm{~cm}^{-1}$ and $1625 \mathrm{~cm}^{-1}$; those can be attributed to stretching vibration 

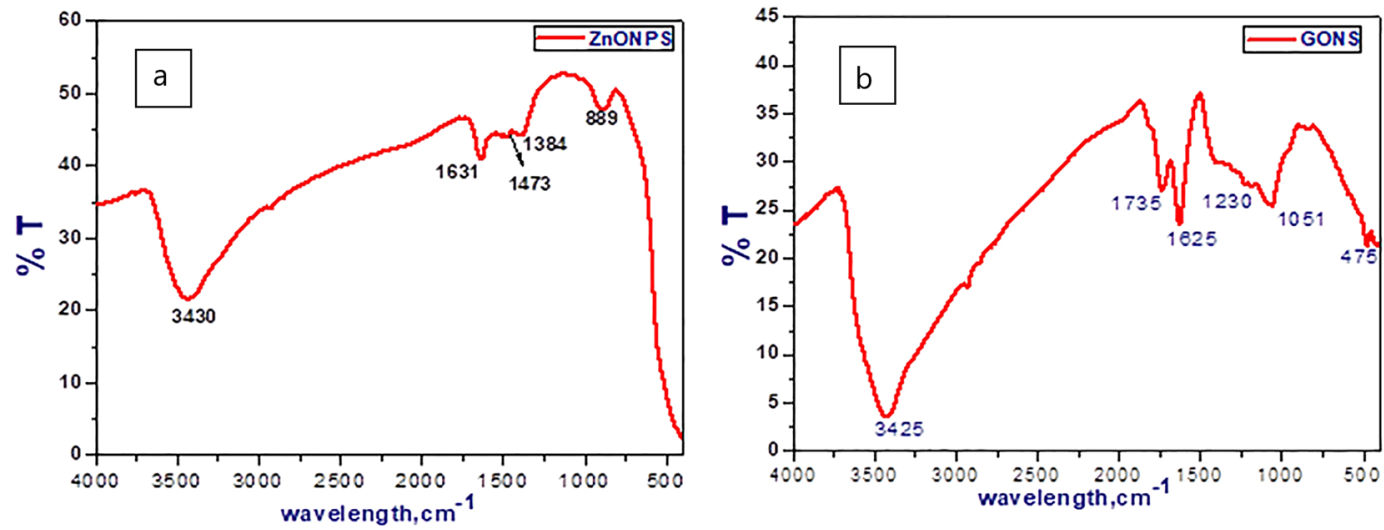

Figure 4. FT-IR chart for (a) ZnONP and (b) GONS.
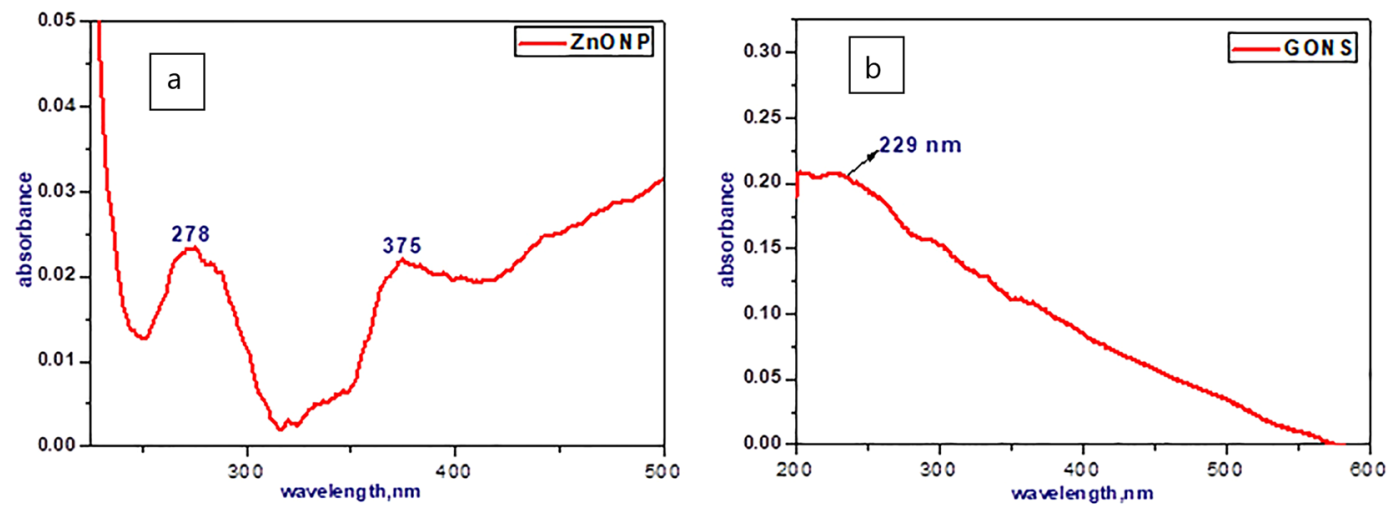

Figure 5. UV-Vis absorption spectrum of (a) ZnONP and (b) GONS.

of $\mathrm{C}=\mathrm{O}$ present in carboxylic and/or carbonyl moiety groups. Furthermore, the two peaks achieved at 1230 and $1051 \mathrm{~cm}^{-1}$ are assigned to the $\mathrm{C}-\mathrm{O}$ stretching vibrations ${ }^{43}$.

The absorption spectra (UV-Vis) measurements. The optical properties of the ZnONP and GONS were studied by measuring their absorption spectra using UV-Vis spectrophotometer. The absorption spectrum of $\mathrm{ZnONP}$ (Fig. 5a) exhibited an excitonic absorption peak at $277 \mathrm{~nm}$ accomplished with another peak around $357 \mathrm{~nm}$ which suggested that the synthesized ZnONP were with high purity and crystallinity; this result was matched with Oladiran et al. ${ }^{44}$. However, the UV-Vis absorption spectrum of a suspended solution of the GONS (Fig. 5b) revealed the appearance of a main peak located at $229 \mathrm{~nm}$, corresponding to the $\pi \rightarrow \pi *$ transitions for aromatic $\mathrm{C}-\mathrm{C}$ bond, and a shoulder appeared at about $302 \mathrm{~nm}$ that can be arising to the $\pi \rightarrow \pi *$ transitions of $\mathrm{C}=\mathrm{O}$ bonds on the surface of $\mathrm{GO}^{45}$. The UV-Vis measurements and the FT-IR results confirm the existence of oxygen functional groups onto GONS.

Preliminary studies for LEVO removal. The preliminary investigation for LEVO removal was evaluated by measuring the absorption spectra of four standard solutions of LEVO $\left(100 \mu \mathrm{g} \mathrm{mL}^{-1}\right)$ at its $\lambda \max (287.5 \mathrm{~nm})$; one solution acted as a control free from NPs, another two were treated with ZnONP and GONS separately, and the fourth one was treated with mixed NPs. After that, the solutions were exposed to UV radiation for 60 min. After the exposure time was finished, the absorption was measured again, while a very small decrease in the absorption was observed for the control sample (Fig. 6a). On the other hand, a significant decrease in the absorption spectra of LEVO was detected after the exposure to UV radiation in the three water samples treated with NPs (Fig. 6b).

Experimental design. The mixed fractional factorial design $\left(2^{4} \times 3^{1}\right)$ was employed to study the significance of each chosen factor and their interactions and to optimize the conditions for maximum removal of LEVO from wastewater as listed in Table 1. Furthermore, the forty-eight samples were analysed by RP-HPLC/UV under variable conditions (Table 2). The optimum conditions for removal of LEVO were noticed at run 35 and 29 as shown in Table 2 at $\mathrm{pH} 9 \pm 0.05$ after exposure to UV radiation for $120 \mathrm{~min}$ in the presence of a combination of $\mathrm{ZnO}: \mathrm{GO}\left(0.4: 1 \mathrm{~g} \mathrm{~L}^{-1}\right)$ for both drug concentrations 50 and $400 \mu \mathrm{g} \mathrm{mL}^{-1}$ as initial concentrations. The results indicated that the optimized condition mention above is independent of the drug concentrations. The removal of the 

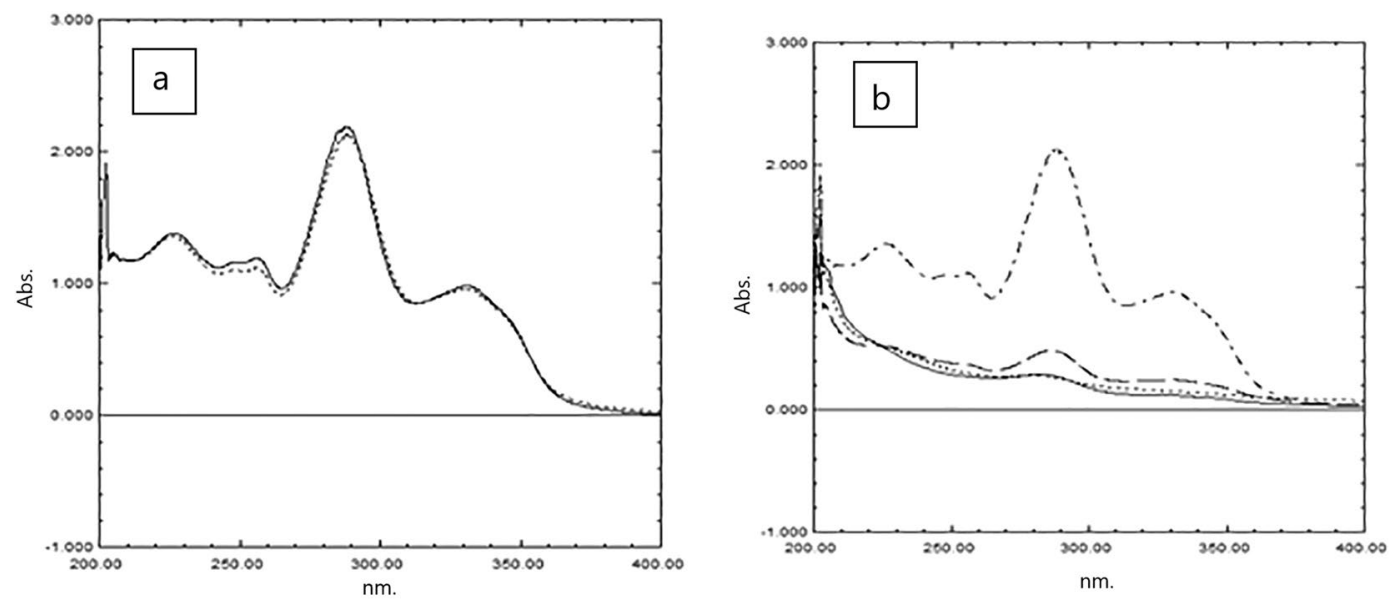

Figure 6. (a) Absorption spectra of LEVO $\left(100 \mu \mathrm{g} \mathrm{mL}^{-1}\right)$ before (.....) and after (__ exposure to UV radiation for $60 \mathrm{~min}$ and (b) Absorption spectra of LEVO $\left(100 \mu \mathrm{g} \mathrm{mL}^{-1}\right)$ (.-.-.) in presence of ZnONP (-), GONP (...) and a combination of (__ $)$ after exposure to UV radiation for $60 \mathrm{~min}$.
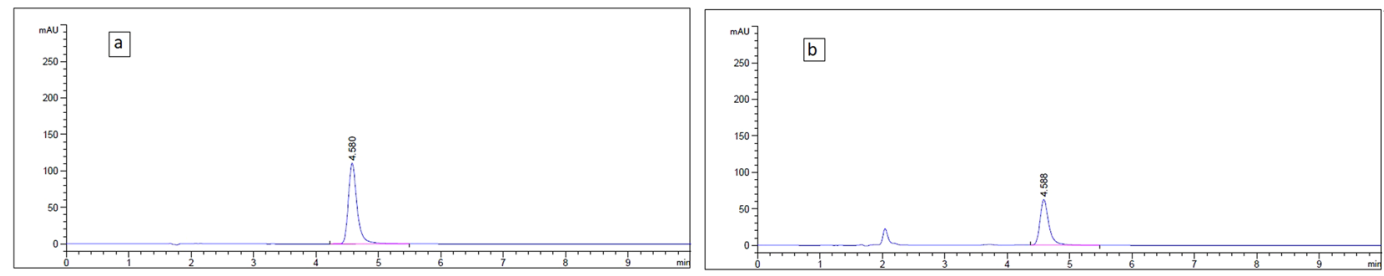

Figure 7. HPLC chromatogram of intact standard LEVO $\left(50 \mu \mathrm{g} \mathrm{mL}^{-1}\right)(\mathbf{a})$ before treatment and (b) after degradation using $1 \mathrm{~g} \mathrm{~L}^{-1} \mathrm{ZnO} \mathrm{NP}$.

drug was effective although an extremely small amount of the NPs can be utilized which was also very beneficial economically.

RP-HPLC/UV analysis method. Different trials were done to obtain a well symmetric peak of the studied drug LEVO, using different mobile phase compositions and different columns $\left(\mathrm{C}_{8}\right.$ and $\left.\mathrm{C}_{18}\right)$. A good resolution was obtained over $4.5 \mathrm{~min}$ using Phenomenex $\mathrm{C}_{18}$ column $(150 \mathrm{~mm} \times 4.6 \mathrm{~mm}, 5 \mu \mathrm{m}$ particle size i.d.) and mobile phase consisting of methanol: phosphate buffer $(\mathrm{pH} 6)$ in a ratio of 50:50 v/v. Isocratic elution was employed at flow rate $1 \mathrm{~mL} \mathrm{m^{-1 }}$ and the UV detection at $294 \mathrm{~nm}$. Figure 7a represented the chromatogram of intact LEVO before treatment and Fig. $7 \mathrm{~b}$ represented it after treatment using $1 \mathrm{~g} \mathrm{~L}^{-1} \mathrm{ZnONP}$. We can observe the great decrease in peak area of LEVO which proved its degradation, while no additional peak was detected which indicated that the drug was degraded to $\mathrm{H}_{2} \mathrm{O}$ and $\mathrm{CO}_{2}$ according to the reported mechanism ${ }^{46}$. The calibration curve for LEVO was constructed showing a linear relationship over the concentration range of $10-500 \mu \mathrm{g} \mathrm{m}^{-1}$. Regression validation parameters and system suitability parameters were calculated according to ICH guidelines summarized in Table $3^{37}$.

Evaluation of the removal efficiency. In this study, ZnONP and GONS were used to remove the traces of LEVO found in pharmaceutical wastewater. According to previous literature, no wastewater treatment was reported using $\mathrm{ZnO}$ and/or GO NPs for the removal of the antibacterial drug LEVO from wastewater. A mixed fractional factorial design $\left(2^{4} \times 3^{1}\right)$ was implemented, and the studied factors $(\mathrm{pH}$, exposure time, nanoparticles type and drug concentration) and their levels were chosen after preliminary trials to optimize the removal process. The studied levels for the $\mathrm{pH}$ factor were $\mathrm{pH}=7$ and 9; at these $\mathrm{pH}$ values, the LEVO has higher susceptibility to photo degradation due to the great reactivity of the ionized species existing in that range ${ }^{47}$. Regarding the LEVO concentration, 50 and $400 \mu \mathrm{g} \mathrm{mL}^{-1}$ were chosen in order to mimic the concentration range of LEVO residues found in pharmaceutical waste samples. It was found that, at LEVO concentration of $500 \mu \mathrm{g} \mathrm{mL}^{-1}$, the active sites $\mathrm{ZnONP}$ and GONS got saturated leading to a decrease in the efficiency of the drug removal percentage, while the maximum percentage achieved was $\sim 10.23 \%$. Subsequently, the maximum concentration of LEVO was carefully chosen to be $400 \mu \mathrm{g} \mathrm{mL}^{-1}$. The ratio of NPs concentration was preferred to be $5: 1$ (ZnONP:GONS) which will promote the photocatalytic efficiency of $\mathrm{ZnO}^{48}$. As obtained from the results, the $\mathrm{ZnONP}$ treated the wastewater samples by photocatalytic effect only; this may be elucidated due to ZnONP's ability to absorb a great quantum of light, promoting the excitation of more electrons ${ }^{49,50}$. In addition, our findings revealed that GONS treated the wastewater samples by adsorption property which may be attributed to the high surface area proven by the BET analysis (about $53 \mathrm{~m}^{2} \mathrm{~g}^{-1}$ ) . Thus, combining these two properties in the two different types of NPs 


\begin{tabular}{|c|c|c|c|}
\hline \multicolumn{2}{|l|}{ Parameters } & HPLC & Reference values* \\
\hline \multicolumn{2}{|l|}{ Linearity $\left(\mu \mathrm{g} \mathrm{mL} L^{-1}\right)$} & $10-500$ & \\
\hline \multicolumn{2}{|l|}{ Correlation coefficient (r) } & 0.9997 & \\
\hline \multicolumn{2}{|l|}{ Slope } & 25.023 & \\
\hline \multicolumn{2}{|l|}{ Intercept } & 22.832 & \\
\hline \multicolumn{2}{|c|}{ Standard deviation of residuals from line } & 23.58 & \\
\hline \multicolumn{2}{|c|}{$\operatorname{LOD}\left(\mu \mathrm{g} \mathrm{mL} L^{-1}\right)$} & 3.109 & \\
\hline \multicolumn{2}{|l|}{ LOQ $\left(\mu \mathrm{g} \mathrm{mL}^{-1}\right)$} & 9.423 & \\
\hline \multicolumn{2}{|l|}{ Accuracy (Recovery $\% \pm S D$ ) } & $99.84 \pm 1.25$ & \\
\hline \multirow{2}{*}{ Precision (RSD) } & Intraday & $100.25 \pm 0.98$ & \\
\hline & Interday & $101 \pm 0.75$ & \\
\hline$t_{R}, \min$ & \multicolumn{2}{|c|}{$4.5 \pm 0.07$} & \\
\hline Tailing factor $(\mathrm{T})$ & \multicolumn{2}{|l|}{0.77} & $\mathrm{~T} \leq 2, \mathrm{~T}=1$ for symmetric peak \\
\hline Capacity factor (K') & \multicolumn{2}{|l|}{1.36} & $\mathrm{~K}^{\prime}=1-10$ acceptable \\
\hline Plates number $(\mathrm{N})$ & \multicolumn{2}{|l|}{5548} & $\mathrm{~N}>2000$ \\
\hline $\begin{array}{l}\text { Height equivalent to theoretical } \\
\text { plate (HETP; } \mathrm{cm}_{\text {plate }}{ }^{-1} \text { ) }\end{array}$ & \multicolumn{2}{|l|}{0.04} & $\begin{array}{l}\text { The smaller the value, the higher } \\
\text { the column efficiency }\end{array}$ \\
\hline
\end{tabular}

Table 3. Summary of system suitability and validation parameters for the proposed HPLC/UV method. *Values defined by FDA Center of Drug Evaluation and Research reviewer guidance on validation of chromatographic methods (November 1994) [Online] Retrieved from www.fda.gov/downloads/Drugs/ Guidances/UCM134409.pdf (accessed April 25, 2015).

\begin{tabular}{|l|l|l|l|l|l|}
\hline Source & Sum of squares & df & Mean square & F value & p-value prob $>$ F \\
\hline Model & $1.18 \times 10^{7-}$ & 20 & $5.91 \times 10^{5-}$ & 1268.36 & $<0.0001$ \\
\hline A-pH & 0.022 & 1 & 0.022 & $4.75 \times 10^{5-}$ & 0.9946 \\
\hline B-Exposure Time & 4465.5 & 1 & 4465.5 & 9.58 & 0.0045 \\
\hline C-Drug Conc & $8.39 \times 10^{5-}$ & 1 & $8.39 \times 10^{5-}$ & 1799.19 & $<0.0001$ \\
\hline D-NP Conc & 830.62 & 1 & 830.62 & 1.78 & 0.1931 \\
\hline E-Type of NP & $9.98 \times 10^{6-}$ & 2 & $4.99 \times 10^{6-}$ & 10698.35 & $<0.0001$ \\
\hline AB interaction & 68.31 & 1 & 68.31 & 0.15 & 0.7049 \\
\hline AC interaction & 11.53 & 1 & 11.53 & 0.025 & 0.8762 \\
\hline AD interaction & 927.33 & 1 & 927.33 & 1.99 & 0.1699 \\
\hline AE interaction & 382.21 & 2 & 191.1 & 0.41 & 0.6678 \\
\hline BC interaction & 343.76 & 1 & 343.76 & 0.74 & 0.3981 \\
\hline BD interaction & 210.22 & 1 & 210.22 & 0.45 & 0.5076 \\
\hline BE interaction & 2491.61 & 2 & 1245.81 & 2.67 & 0.0873 \\
\hline CD interaction & 869.88 & 1 & 869.88 & 1.87 & 0.1832 \\
\hline CE interaction & $9.99 \times 10^{5-}$ & 2 & $5.00 \times 10^{5-}$ & 1071.78 & $<0.0001$ \\
\hline DE interaction & 2351.57 & 2 & 1175.78 & 2.52 & 0.099 \\
\hline Residual & 12587.69 & 27 & 466.21 & & \\
\hline
\end{tabular}

Table 4. ANOVA for Response Surface 2FI model and analysis of variance.

(the photocatalytic activity of ZnONP and the high adsorption effect of GONS) will enhance the removal rate of LEVO residues.

Analysis of the results. Analysis of the mixed fractional factorial design results was carried out at a 95\% confidence level using the percentage of the drug removal as the response factor. The significance of one factor has minimal effect in which R squared was 0.882 , so the study of the interaction between two factors was favored and this was proven by the high $\mathrm{R}$ square value $=0.9966$. ANOVA was carried out and the results were summarized in Table 4. The values of "Prob $>F$ " indicated the significance of the factors if it was less than 0.05 . The most significant factors on the removal efficiency were the drug concentration and the NPs types. On the other hand, the NPs concentration, the $\mathrm{pH}$ and the exposure time did not have an impact on the drug removal process as shown in Fig. 8. The interaction between the drug concentration (C) and nanoparticles concentration (E) sustained the highest impact on drug removal when all other factors were kept constant (Fig. 4, supplemental materials). From the results, we conclude that the usage of $\mathrm{ZnONP}$ alone did not significantly affect the removal process, as the maximum removal obtained was $34.12 \%$ with concentration of $1 \mathrm{gL}^{-1}$. The GONS has a better effect, as $91.87 \%$ of removal was achieved; this may be because the surface area of GONS is larger than that of ZnONP. The optimum drug removal percentage obtained using the combination of both $\mathrm{ZnONP}$ and GONS was 99.6\%. Figure 5, supplemental materials represents the normal probability plots of residual values of the LEVO treated samples. 


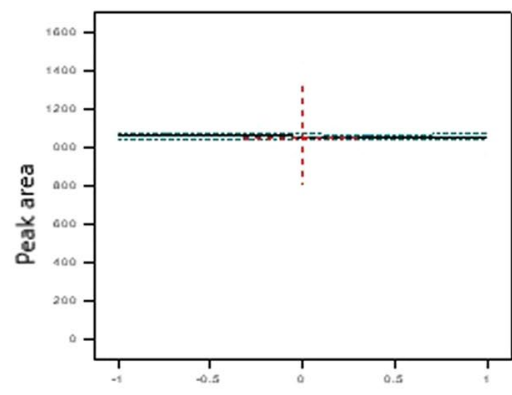

A. $\mathrm{PH}$

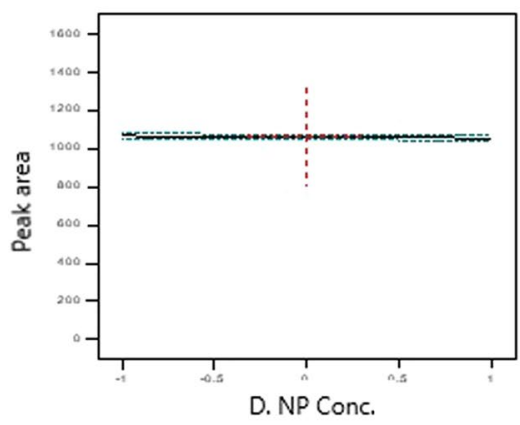

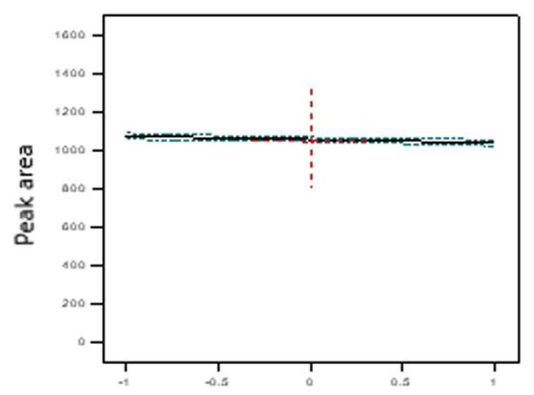

B. Exposure Time (min)

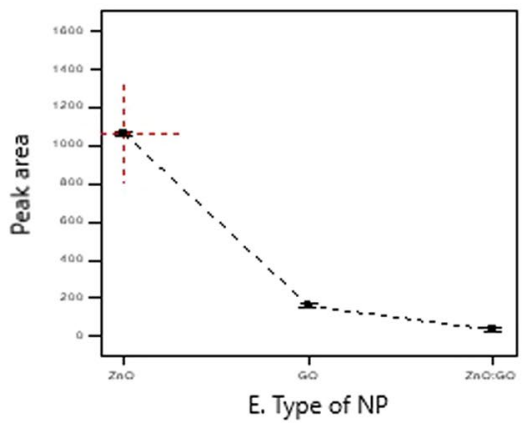

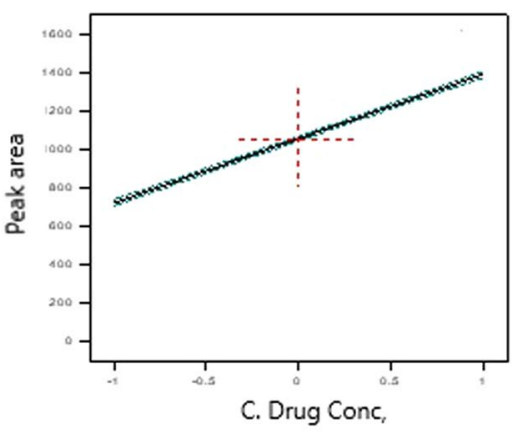

Figure 8. Significance of single factors on removal of LEVO.

\begin{tabular}{|c|c|}
\hline $\begin{array}{l}\text { Final Equation in Terms } \\
\text { of Coded Factors }\end{array}$ & 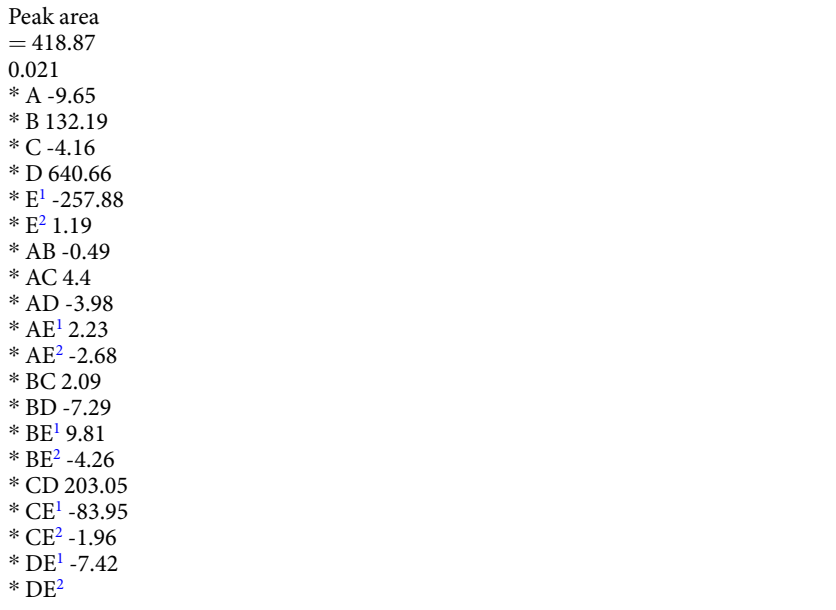 \\
\hline $\begin{array}{l}\text { Final Equation in Terms } \\
\text { of Actual Factors }\end{array}$ & $\begin{array}{l}\text { Peak area }(\mathrm{ZnO}: \mathrm{GO}) \\
=36.09016 \\
1.77765^{*} \mathrm{pH}-12.15985^{*} \text { Exposure Time } 13.09875^{*} \text { Drug Conc } 5.22234^{*} \mathrm{NP} \text { Conc } \\
1.19297^{*} \mathrm{pH} * \text { Exposure Time }-0.49016^{*} \mathrm{pH} * \text { Drug Conc 4.39537* pH * NP Conc } \\
-2.67612^{*} \text { Exposure Time * Drug Conc 2.09275* Exposure Time * NP Conc }-4.25704 \\
\text { * Drug Conc* NP Conc }\end{array}$ \\
\hline
\end{tabular}

Table 5. Regression Equations Summarizing the Experimental Design for LEVO.

The $\mathrm{P}$ values $(\mathrm{P}>0.05)$ indicate that the experimental points were normally distributed. The regression equation was summarized in Table 5. The 3D and contour plots show the extent of decrease in the drug concentration as a function of exposure under UV light with a constant $\mathrm{pH}$, drug concentration and type of nanoparticles $(\mathrm{ZnONP})$ (Fig. 9). The obtained plots agreed with the statistical ANOVA results as shown in Table 4. The performed design predicted that the most effective factors to enhance the LEVO removal (99.6\%) were obtained at a lower initial concentration $\left(50 \mu \mathrm{g} \mathrm{mL}^{-1}\right)$ by means of irradiation time of $120 \mathrm{~min}$ and at $\mathrm{pH}=7 \mathrm{using}$ a combination of ZnONP:GONS in ratio 0.4:1 $\mathrm{g} \mathrm{L}^{-1}$ (Table 6, run 35), while for $400 \mu \mathrm{g} \mathrm{mL}^{-1}$ LEVO initial concentration the drug removal percentage was found to be $99.21 \%$ using also a combination of ZnONP:GONS in ratio $0.4: 1 \mathrm{gL}^{-1}$ having the same conditions (Table 6, run 29).

Application to pharmaceutical wastewater samples. According to the pharmaceutical manufacturer's protocol, the cleaning procedure was done using boiling distilled water for three successive cycles. The 

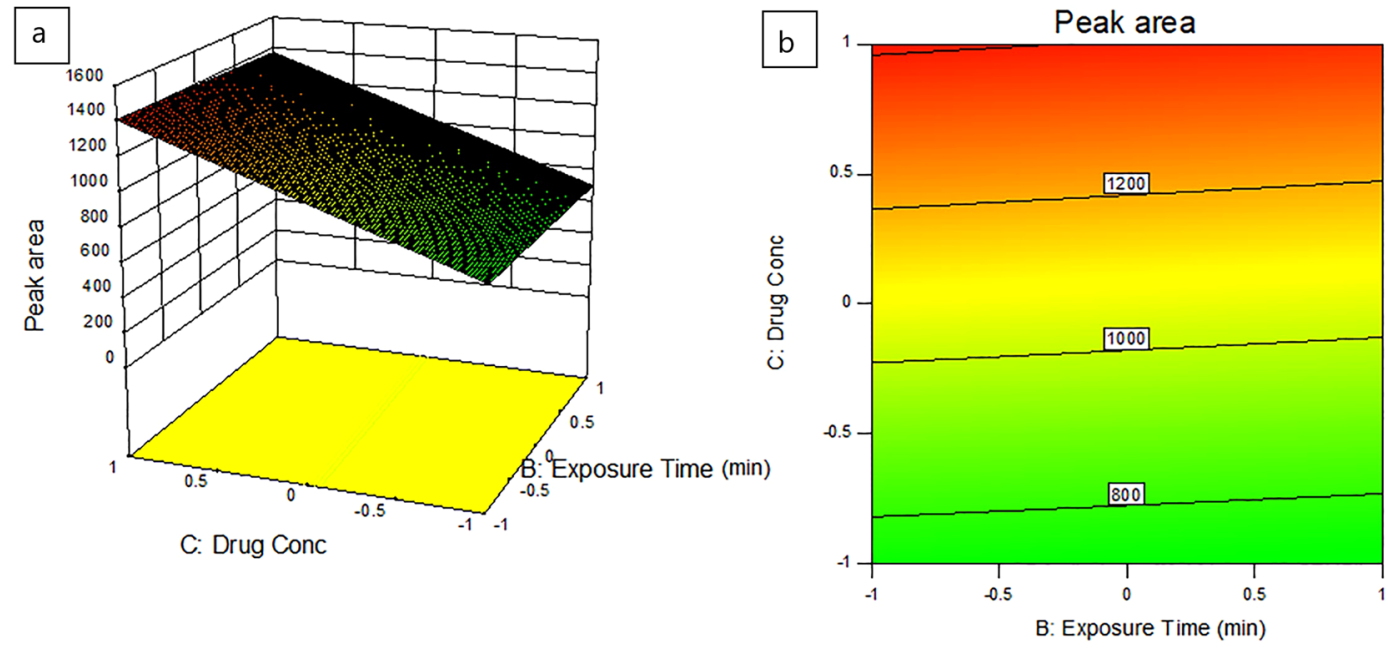

Figure 9. 3D plot (a) and contour plot (b) of the peak area of LEVO degraded samples as a result of effect of exposure time and drug concentration.

\begin{tabular}{|l|l|l|l|l|l|l|l|l|}
\hline Number & $\mathbf{p H}$ & $\begin{array}{l}\text { Exposure } \\
\text { Time }\end{array}$ & $\begin{array}{l}\text { Drug } \\
\text { Conc }\end{array}$ & $\begin{array}{l}\text { NP } \\
\text { Conc }\end{array}$ & $\begin{array}{l}\text { Type of } \\
\text { NP }\end{array}$ & $\begin{array}{l}\text { Peak } \\
\text { area }\end{array}$ & Desirability & \\
\hline 1 & $\underline{-1}$ & $\underline{1}$ & $\underline{-1}$ & $\underline{-1}$ & $\underline{\text { ZnO:GO }}$ & $\underline{2.87}$ & $\underline{1}$ & $\underline{\text { Selected }}$ \\
\hline 2 & -1 & 0.983 & -0.958 & -0.982 & ZnO:GO & 3.854 & 1 & \\
\hline 3 & -1 & 0.965 & -0.981 & -0.967 & ZnO:GO & 3.847 & 1 & \\
\hline
\end{tabular}

Table 6. Solutions for the three combinations of categorical factor levels.

concentration of LEVO in the collected samples of cleaning lines was found to be around $250 \mu \mathrm{g} \mathrm{mL}^{-1}$ according to RP-HPLC/UV method of analysis, while the optimum conditions were applied as described above on this collected samples. After treatment using the designed NPs, the percentages of removal were $98.84 \pm 0.02 \%$ and $99.17 \pm 0.36 \%$ for the pharmaceutical wastewater and control samples, respectively. No significant difference in the drug removal percentage was detected which indicates the efficacy of the developed protocol and absence of matrix interference.

Evaluation of antibacterial activity. The agar diffusion method was carried out to confirm the effective degradation of LEVO using the standard strain Escherichia coli ATCC 25922. The effect of adsorption and photocatalytic removal of LEVO by the combined mix of ZnONP and GONS was determined by measuring the diameter of the Escherichia coli inhibition zone formed. As shown in the results (Fig. 6, supplemental materials), no inhibition zone was formed around the treated wastewater sample in the agar diffusion assay. On the other hand, a $22 \mathrm{~mm}$ diameter zone was detectable for the untreated wastewater sample. This indicates the lack of antimicrobial activity for treated wastewater that may be referring to the absence of the antibiotic drug in water and the effective removal of LEVO from wastewater.

\section{Conclusion}

In summary, two nanoparticles, ZnONP and GONS, and their combined form, ZnONP/GONS, were successfully fabricated and fully characterized. They have been efficiently used for the adsorptive and photocatalytic removal of LEVO from pharmaceutical wastewater. The removal efficiency was evaluated using a mixed fractional factorial design to study the influence of various factors (such as $\mathrm{pH}$, the exposure time to UV radiation, the type and concentration of the NPs and the initial concentration of the antibiotic) on the potential of removal process. All the provided factors showed a significant effect except the $\mathrm{pH}$ and the exposure time. Furthermore, the highest removal rate was achieved using the combined nanostructure ZnONP/GONS; hence, it was applied on collected pharmaceutical wastewater samples containing LEVO residues (delivered from Egyptian pharmaceutical company) following the optimum condition. The treatment method was successfully applied for low and high antibiotic concentration levels. Subsequently, it proved to be an efficient material utilized for the removal of other antibiotics from aquatic water.

Received: 2 September 2019; Accepted: 26 February 2020;

Published online: 03 April 2020

\section{References}

1. Kümmerer, K. Significance of antibiotics in the environment. Journal of Antimicrobial Chemotherapy 52(1), 5-7 (2003).

2. Ahmed, M. B. et al. Adsorptive removal of antibiotics from water and wastewater: Progress and challenges. Science of the Total Environment 532, 112-126 (2015). 
3. Hirsch, R. et al. Occurrence of antibiotics in the aquatic environment. Science of the Total environment 225(1-2), 109-118 (1999).

4. Kolpin, D. W. et al. Pharmaceuticals, hormones, and other organic wastewater contaminants in US streams, 1999-2000: A national reconnaissance. Environmental science \& technology 36(6), 1202-1211 (2002).

5. Ashton, D., Hilton, M. \& Thomas, K. Investigating the environmental transport of human pharmaceuticals to streams in the United Kingdom. Science of the total environment 333(1-3), 167-184 (2004).

6. Wise, R. et al. Antimicrobial resistance is a major threat to public health. British Medical Journal 317, 609-610 (1998).

7. Hooper, D. C. \& Rubinstein, E. Quinolone antimicrobial agents. (ASM Press, Washington, D.C, 2003).

8. Hu, J. et al. Quantitative Structure-Activity Relationship Model for Prediction of Genotoxic Potential for Quinolone Antibacterials. Environmental Science \& Technology 41(13), 4806-4812 (2007).

9. Watkinson, A., Murby, E. \& Costanzo, S. Removal of antibiotics in conventional and advanced wastewater treatment: Implications for environmental discharge and wastewater recycling. Water Research 41(18), 4164-4176 (2007).

10. Sharma, G. et al. Fabrication and characterization of chitosan-crosslinked-poly (alginic acid) nanohydrogel for adsorptive removal of $\mathrm{Cr}$ (VI) metal ion from aqueous medium. International journal of biological macromolecules 95, 484-493 (2017).

11. Naushad, M., Sharma, G. \& Alothman, Z. A. Photodegradation of toxic dye using Gum Arabic-crosslinked-poly (acrylamide)/Ni (OH) 2/FeOOH nanocomposites hydrogel. Journal of Cleaner Production 241, 118263 (2019).

12. Sharma, G. et al. Fabrication and characterization of Gum arabic-cl-poly (acrylamide) nanohydrogel for effective adsorption of crystal violet dye. Carbohydrate polymers 202, 444-453 (2018).

13. Göbel, A. et al. Fate of sulfonamides, macrolides, and trimethoprim in different wastewater treatment technologies. Science of the Total Environment 372(2-3), 361-371 (2007).

14. Vieno, N. M. et al. Occurrence of pharmaceuticals in river water and their elimination in a pilot-scale drinking water treatment plant. Environmental science \& technology 41(14), 5077-5084 (2007).

15. Homem, V. \& Santos, L. Degradation and removal methods of antibiotics from aqueous matrices-a review. Journal of environmental management 92(10), 2304-2347 (2011).

16. Kurt, A. et al. Treatment of Antibiotics in Wastewater Using Advanced Oxidation Processes (AOPs),Physico-Chemical Wastewater Treatment and Resource Recovery. Croatia: INTECH (2017).

17. Kansal, S. K. et al. Photocatalytic degradation of the antibiotic levofloxacin using highly crystalline TiO2 nanoparticles. New Journal of Chemistry 38(7), 3220-3226 (2014).

18. An, T. et al. Mechanistic Considerations for the Advanced Oxidation Treatment of Fluoroquinolone Pharmaceutical Compounds using TiO2 Heterogeneous Catalysis. The Journal of Physical Chemistry A 114, 2569-2575 (2010).

19. Sturini, M. et al. Photolytic and photocatalytic degradation of fluoroquinolones in untreated river water under natural sunlight. Applied Catalysis B: Environmental 119-120, 32-39 (2012).

20. Kaur, A. \& Kansal, S. K. Bi 2 WO 6 nanocuboids: An efficient visible light active photocatalyst for the degradation of levofloxacin drug in aqueous phase. Chemical Engineering Journal 302, 194-203 (2016).

21. Gupta, G. et al. Photocatalytic degradation of levofloxacin in aqueous phase using $\mathrm{Ag} / \mathrm{AgBr} / \mathrm{BiOBr}$ microplates under visible light. Materials Research Bulletin 88, 148-155 (2017).

22. Kaur, A. et al. Visible light driven photocatalytic degradation of fluoroquinolone levofloxacin drug using Ag2O/TiO2 quantum dots: a mechanistic study and degradation pathway. New Journal of Chemistry 41(20), 12079-12090 (2017).

23. Attallah, O. A. et al. Adsorptive Removal of Fluoroquinolones from Water by Pectin-Functionalized Magnetic Nanoparticles: Process Optimization Using a Spectrofluorimetric Assay. ACS Sustainable Chemistry \& Engineering 5(1), 133-145 (2017).

24. Li, Q. et al. Antimicrobial nanomaterials for water disinfection and microbial control: potential applications and implications. Water research 42(18), 4591-4602 (2008).

25. Qiao, Y. et al. A bench-scale assessment of ozone pre-treatments for landfill leachates. Environmental technology 35(2), 145-153 (2014).

26. Mostafaii, G. et al. Investigation of Zinc Oxide Nanoparticles Effects on Removal of Total Coliform Bacteria in Activated Sludge Process Effluent of Municipal Wastewater. Journal of Environmental Science and Technology 10, 49-55 (2017).

27. Gottschalk, F. et al. Modeled environmental concentrations of engineered nanomaterials ( $\mathrm{TiO} 2, \mathrm{ZnO}, \mathrm{Ag}$, CNT, fullerenes) for different regions. Environmental science \& technology 43(24), 9216-9222 (2009).

28. Sun, T. Y. et al. Comprehensive probabilistic modelling of environmental emissions of engineered nanomaterials. Environmental pollution 185, 69-76 (2014).

29. Peng, C. et al. Intracellular imaging with a graphene-based fluorescent probe. Small 6(15), 1686-1692 (2010).

30. Wei, Y. et al. Multilayered graphene oxide membrane for water treatment: a review. Carbon (2018).

31. Liu, Y. Application of graphene oxide in water treatment. In IOP Conference Series: Earth and Environmental Science. IOP Publishing (2017).

32. Beek, W. J. et al. Hybrid zinc oxide conjugated polymer bulk heterojunction solar cells. The Journal of Physical Chemistry B 109(19), 9505-9516 (2005).

33. Pacholski, C., Kornowski, A. \& Weller, H. Self-Assembly of ZnO: From Nanodots to Nanorods. Angewandte Chemie International Edition 41(7), 1188-1191 (2002).

34. Marcano, D. C. et al. Improved Synthesis of Graphene Oxide. ACS Nano 4(8), 4806-4814 (2010).

35. McAllister, M. J. et al. Single Sheet Functionalized Graphene by Oxidation and Thermal Expansion of Graphite. Chemistry of Materials 19(18), 4396-4404 (2007)

36. Kudin, K. N. et al. Raman Spectra of Graphite Oxide and Functionalized Graphene Sheets. Nano Letters 8(1), 36-41 (2008).

37. ICH-International Conference on Harmonization, of Technical Requirements for registration of Pharmaceuticals for Human Use Topic Q2 (R1), Validation of Analytical Procedures: Text and Methodology, Geneva, Switzerland (2005).

38. Kansal, S. K. et al. Photocatalytic degradation of the antibiotic levofloxacin using highly crystalline $\mathrm{TiO} 2$ nanoparticles. New Journal of Chemistry 38(7), 3220-3226 (2014).

39. Dreyer, D. R. et al. The chemistry of graphene oxide. Chemical society reviews 39(1), 228-240 (2010).

40. Fernandez, T. et al. An ultra-low hydrolysis sol-gel route for titanosilicate xerogels and their characterization. Journal of sol-gel science and technology 41(2), 163-168 (2007).

41. Chen, Y.-L. et al. Zinc oxide/reduced graphene oxide composites and electrochemical capacitance enhanced by homogeneous incorporation of reduced graphene oxide sheets in zinc oxide matrix. The Journal of Physical Chemistry C 115(5), 2563-2571 (2011).

42. Kumar, H. \& Rani, R. Structural and optical characterization of $\mathrm{ZnO}$ nanoparticles synthesized by microemulsion route. International Letters of Chemistry, Physics and Astronomy 14, 26-36 (2013).

43. Chaiyakun, S. et al. Preparation and characterization of graphene oxide nanosheets. Procedia Engineering 32, 759-764 (2012).

44. Oladiran, A. A. \& Olabisi, I. A.-M. Synthesis and characterization of $\mathrm{ZnO}$ nanoparticles with zinc chloride as zinc source. IOSR Journal of Applied Physics, 2(2) (2013).

45. Sun, X. et al. Nano-graphene oxide for cellular imaging and drug delivery. Nano research 1(3), 203-212 (2008).

46. Mokhbi, Y. et al. Treatment Heterogeneous Photocatalysis; Factors Influencing the Photocatalytic Degradation by TiO2. Energy Procedia 50, 559-566 (2014).

47. Ahmad, I. et al. Photodegradation of levofloxacin in aqueous and organic solvents: a kinetic study. Acta pharmaceutica (Zagreb, Croatia) 63(2), 223-229 (2013). 
48. Raliya, R. et al. Photocatalytic degradation of methyl orange dye by pristine titanium dioxide, zinc oxide, and graphene oxide nanostructures and their composites under visible light irradiation. Applied Nanoscience 7(5), 253-259 (2017).

49. Sakthivel, S. et al. Solar photocatalytic degradation of azo dye: comparison of photocatalytic efficiency of $\mathrm{ZnO}$ and $\mathrm{TiO}$. Solar Energy Materials and Solar Cells 77(1), 65-82 (2003).

50. Sun, M. et al. Natural biological template for $\mathrm{ZnO}$ nanoparticle growth and photocatalytic dye degradation under visible light. RSC Advances 5(103), 84406-84409 (2015).

51. Nguyen-Phan, T.-D. et al. The role of graphene oxide content on the adsorption-enhanced photocatalysis of titanium dioxide/ graphene oxide composites. Chemical Engineering Journal 170(1), 226-232 (2011).

\section{Acknowledgements}

Dr. Christine El-Maraghy and Dr. Omnia A.ElNaem, did the excremental design and practical work. While Dr.Ola El-Borady, synthesized the nano particles and did all the characterizations. All authors contributed in writing the manuscript.

\section{Competing interests}

The authors declare no competing interests.

\section{Additional information}

Supplementary information is available for this paper at https://doi.org/10.1038/s41598-020-61742-4.

Correspondence and requests for materials should be addressed to O.A.E.-N.

Reprints and permissions information is available at www.nature.com/reprints.

Publisher's note Springer Nature remains neutral with regard to jurisdictional claims in published maps and institutional affiliations.

(c) (i) Open Access This article is licensed under a Creative Commons Attribution 4.0 International License, which permits use, sharing, adaptation, distribution and reproduction in any medium or format, as long as you give appropriate credit to the original author(s) and the source, provide a link to the Creative Commons license, and indicate if changes were made. The images or other third party material in this article are included in the article's Creative Commons license, unless indicated otherwise in a credit line to the material. If material is not included in the article's Creative Commons license and your intended use is not permitted by statutory regulation or exceeds the permitted use, you will need to obtain permission directly from the copyright holder. To view a copy of this license, visit http://creativecommons.org/licenses/by/4.0/.

(c) The Author(s) 2020 